\title{
Menentukan Rute Terpendek Pendistribusian Bahan Bangunan oleh PT. Sadar Jaya Manunggal Mataram Menggunakan Algoritma Branch and Bound
}

\section{Lalu Abd Azis Mursy ${ }^{a, *}$, Hibban Kholiq ${ }^{b}$, Diah Ayu Saptyaningtyas ${ }^{c}$, Rina Julianad, Mira Sulisdiana ${ }^{e}$, Mamika Ujianita Rhomdini ${ }^{f}$}

${ }^{a}$ Program Studi Matematika, FMIPA, Universitas Mataram, Jl. Majapahit No.62, Mataram, 83125, Indonesia. Email: azizazure4@gmail.com

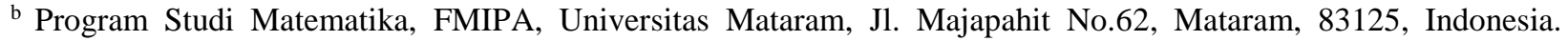
Email: hibbankholiq@gmail.com

${ }^{c}$ Program Studi Matematika, FMIPA, Universitas Mataram, Jl. Majapahit No.62, Mataram, 83125, Indonesia. Email: saptya0799@gmail.com

${ }^{\mathrm{d}}$ Program Studi Matematika, FMIPA, Universitas Mataram, Jl. Majapahit No.62, Mataram, 83125, Indonesia. Email: rina.juliana@unram.ac.id

${ }^{\text {e }}$ Program Studi Matematika, FMIPA, Universitas Mataram, J1. Majapahit No.62, Mataram, 83125, Indonesia. Email: mirasulisdiana1@gmail.com

${ }^{\mathrm{f}}$ Program Studi Matematika, FMIPA, Universitas Mataram, Jl. Majapahit No.62, Mataram, 83125, Indonesia. Email: mamika_ur@yahoo.com

\section{A B S T R A C T}

PT Sadar Jaya Manunggal is one of several companies engaged in supplying building materials. This company has a lot of branches in Indonesia, one of which is located in Mataram City, at 78 TGH Faisal street. Everyday, the company distributes building materials to its customers. This activity takes various amounts of time and money, depending on the distance to each delivery destination. Therefore it raises the challenge of keeping the cost and time to a minimum, so that the company makes maximum profits. This problem is called the traveling salesman problem. The traveling salesman problem refers to the challenge of finding the shortest routes to distribute building materials to all consumers. The solution to this problem is to represent the map for the purpose of distributing in the form of a weighted complete graph, then the problem can be solved by using Branch and Bound algorithm. Based on calculations using the Branch and Bound algorithm for the optimization of the distribution routes, building materials are delivered by PT Sadar Jaya Manunggal Mataram, with the optimal routes: (PT. Sadar Jaya Manunggal - UD. Mitra Utama - Pos Bangunan - Kunci Pelita - UD. Budi Rahman - Kurnia Jaya - UD. Salha - Ikhlas Bersama PT. Sadar Jaya Manunggal) with a total distance of 122,3 kilometers.

Keywords : Branch and Bound Algorithm; Distribution; Travelling Salesman Problem

* Corresponding author.

Alamat e-mail: azizazure4@gmail.com 


\section{A B S T R A K}

PT. Sadar Jaya Manunggal merupakan salah satu perusahaan yang bergerak dalam pengadaan bahan bangunan. Perusahaan ini memiliki banyak cabang di kota-kota besar Indonesia, salah satunya di Kota Mataram yaitu di Jalan TGH. Faisal 78. Setiap hari, perusahaan akan melakukan pendistribusian bahan bangunan kepada para konsumen. Kegiatan pendistribusian ini memakan biaya dan waktu yang dipengaruhi oleh jarak setiap tempat yang menjadi tujuan pendistribusian, sehingga timbulah masalah bagaimana agar kegiatan pendistribusian ini memakan biaya dan waktu seminimal mungkin, sehingga perusahaan memperoleh keuntungan yang optimal. Masalah tersebut merupakan bentuk Travelling Salesman Problem yaitu mencari rute terpendek untuk pendistribusian bahan bangunan kepada semua konsumen. Pemecahan permasalahan tersebut adalah dengan merepresentasikan peta tujuan pendistribusian atau alamat para konsumen ke dalam bentuk graf lengkap berbobot, selanjutnya permasalahan diselesaikan menggunakan Algoritma Branch and Bound. Berdasarkan perhitungan menggunakan Algoritma Branch and Bound untuk optimasi rute pendistribusian bahan bangunan oleh PT. Sadar Jaya Manunggal Mataram menghasilkan solusi rute: (PT. Sadar Jaya Manunggal Mataram - UD. Mitra Utama - Pos Bangunan - Kunci Pelita - UD. Budi Rahman - Kurnia Jaya - UD. Salha - Ikhlas Bersama - PT. Sadar Jaya Manunggal Mataram) dengan total jarak $122,3 \mathrm{~km}$.

Kata Kunci: Algoritma Branch and Bound; Pendistribusian; Travelling Salesman Problem

Diserahkan: 16-05-2019; Diterima: 28-06-2019;

Doi: https://doi.org/10.29303/emj.v1i1.24

\section{Pendahuluan}

Saat ini dunia usaha mengalami perkembangan ynag sangat pesat, baik usaha perdagangan, industri maupun jasa. Oleh karena itu, perusahaan dituntut untuk mampu bersaing dan tetap aktif dalam proses pemasaran sehingga peningkatan penjualan dan pendapatan yang diinginkan bisa tercapai. Meningkatnya permintaan pasar terhadap produk memberikan peluang kepada para produsen untuk memenuhi kebutuhan pasar yang potensial. Salah satunya yaitu perusahaan yang bergerak di bidang industri.

PT. Sadar Jaya Manunggal merupakan salah satu perusahaan yang menyediakan bahan-bahan bangunan dan berusaha untuk menjangkau pasar yang lebih luas dengan cara mendirikan cabangcabang distributor di beberapa kota besar yang ada di Indonesia. Salah satu cabang distributor didirikan berada di Jalan TGH Faisal No. 78 Mataram, Nusa Tenggara Barat. Hal ini dilakukan karena distribusi menjadi bagian penting dalam proses pemasaran dan untuk mempermudah pendistribusian produk ke konsumen.

Masalah utama dalam pendistribusian produk adalah bagaimana caranya agar produk tersebut dapat melewati jalur-jalur tertentu dari sumbersumber yang menyediakan produk ke tempattempat tujuan sehingga biaya yang dikeluarkan seminimal mungkin dan waktu yang digunakan seefesien mungkin. Masalah optimasi untuk meminumkan jarak dan biaya distribusi disebut
Travelling Salesman Problem (TSP). Terdapat beragam algoritma yang dapat digunakan untuk menyelesaikan permasalahan Travelling Salesmen Problem (TSP) seperti, algoritma brute force, algoritma greedy, algoritma genetic, algoritma Branch and Bound dll.

Dalam rangka menemukan rute perjalanan yang paling optimum untuk permasalahan pendistribusian bahan bangunan oleh PT Sadar Jaya Manunggal, salah satu algoritma yang dapat digunakan yaitu algoritma Branch and Bound. Metode ini mampu menyelesaikan permasalahan seperti Travelling Salesmen Problem (TSP) dan beberapa masalah lain. Konsep utama metode Branch and Bound adalah membagi masalah aslinya yang berukuran besar menjadi sub masalah yang lebih kecil kemudian menjadi anak gugus yang lebih kecil lagi sampai semua sub masalah dapat diselesaikan (Hillier, 2001).

Metode ini menggunakan pohon pencarian (Search Tree), dimana setiap simpul di pohon merupakan representasi dari sejumlah kemungkinan solusi dari Travelling Salesmen Problem (TSP). Algoritma Branch and Bound sering digunakan untuk menyelesaikan masalah Travelling Salesmen Problem (TSP) karena hasil yang diperoleh dalam penyelesaian optimal lebih teliti dan lebih baik dari metode lain. Dikatakan lebih baik dan teliti dari metode lain karena hasil optimum yang diperoleh biasanya lebih dari satu, sehingga penulis dapat menentukan hasil yang paling optimal dari hasil-hasil yang telah diperoleh (Sitorus, 1997). 


\section{Landasan Teori}

\subsection{Pendistribusian}

Distribusi adalah kegiatan penyaluran hasil produksi berupa barang dan jasa dari produsen ke konsumen guna memenuhi kebutuhan manusia. Distribusi bertujuan agar benda-benda hasil produksi sampai kepada konsumen dengan lancar, tetapi harus memperhatikan kondisi produsen dan sarana yang tersedia dalam masyarakat,di mana sistem distribusi yang baik akan sangat mendukung kegiatan produksi dan konsumsi (Avidianto, 2010).

\subsection{Graf}

Graf pertama kali ditemukan oleh Leonhard Euler, seorang matematikawan kebangsaan Swiss pada tahun 1736. Dimana saat itu Euler berhasil menulis upaya pemecahan Jembatan Koningsberg yang terkenal di Rusia. Graf merupakan sebuah kumpulan yang terdiri dari titik (vertex) dan garis dimana pasangan titik - titik tersebut dihubungkan dengan segmen garis. Verteks ini sering disebut sebagai titik dan segmen garis disebut sebagai edge. Maka direpresentasikan dengan (Lipschutz, 2002).

\subsection{Travelling Salesman Problem (TSP)}

Bentuk umum dari TSP pertama dipelajari oleh para matematikawan mulai tahun 1930. Diawali oleh Karl Menger di Viena dan Harvard. Setelah itu permasalahan TSP dipublikasikan oleh Hassler Whitney dan Merrill Flood di Princeton. Selanjutnya dengan permasalahan ini, TSP dibuat menjadi permasalahan yang terkenal dan popular untuk dipakai sebagai model produksi, transportasi dan komunikasi (Amin, dkk, 2006).

\subsection{Algoritma Branch and Bound}

Algoritma Branch and Bound merupakan algoritma yang membagi permasalahan menjadi sub masalah lebih kecil yang mengarah ke solusi dengan pencabangan (branching) dan melakukan pembatasan (bounding) untuk mencapai solusi optimal. Pencabangan (branching) yaitu proses membentuk permasalahan kedalam bentuk struktur pohon pencarian (search tree). Proses Pencabangan dilakukan untuk membangun semua cabang pohon yang menuju solusi, sedangkan proses pembatasan dilakukan dengan menghitung estimasi nilai (cost) simpul dengan memperhatikan batas (Suyanto, 2010).
Secara umum algoritma Branch and Bound dalam melakukan pencarian solusi menggunakan teknik Least Cost Search atau pencarian nilai terkecil, teknik ini akan menghitung nilai (cost) setiap simpul. Simpul yang memiliki nilai paling kecil dikatakan memiliki kemungkinan paling besar menuju solusi. Setiap simpul aktif (current node) mempunyai sebuah nilai yang menyatakan nilai batas (bound). Sebuah simpul aktif merupakan simpul yang mempunyai nilai batas terkecil (karena teknik pencarian solusi Least Cost Search) (Eko Budi P, 2008).

Misal $i$ adalah nilai estimasi lintasan minimum dari simpul $i$ ke simpul tujuan, jadi $c(i)$ menyatakan batas (bound) nilai pencarian solusi dari simpul $i$. Sehingga dapat dirumuskan fungsi heuristic untuk menghitung nilai estimasi sebagai berikut:

$$
c(i)=f(i)+g(i)
$$

dengan:

$$
c(i) \text { : Nilai untuk simpul } i
$$

$f(i)$ : Nilai lintasan dari simpul akar ke simpul $i$

$g(i)$ : Nilai untuk mencapai simpul tujuan dari simpul $i$

Untuk permasalahan yang lebih kompleks, sistem digambarkan dengan matriks $A$ ukuran $n \times n$. Untuk dipilih simpul mana yang akan dieksplorasi. Simpul yang dieksplorasi adalah simpul dengan nilai batas terkecil. Nilai batas didapatkan dari reduksi baris dan kolom matriks $A$ yang merepresentasikan graf. Reduksi dilakukan dengan mengurangi nilai $c_{i j}$ pada baris atau kolom dengan nilai $c_{i j}$ terkecil pada baris atau kolom tersebut, sedemikian sehingga didapatkan matriks tereduksi ${ }^{t}$ dengan sebuah nilai nol pada setiap baris dan kolom. Sebuah matriks dikatakan tereduksi jika setiap kolom dan barisnya mengandung minimal satu nilai nol dan semua elemen lainnya non-negatif. Selanjutnya total nilai pereduksi menjadi nilai batas simpul akar. Untuk setiap simpul anak yang dibangkitkan dengan mengunjungi $(i, j)$, dilakukan reduksi matriks $A(t)$ untuk mendapatkan matriks tereduksi $A(j$, simpul awal $)$ diubah menjadi $\infty$.

Berdasarkan persamaan fungsi heuristik untuk menghitung nilai estimasi yang telah dijelaskan sebelumnya, maka nilai batas simpul anak dihitung dengan rumus:

$$
\hat{c}(S)=\hat{c}(R)+A(i, j)+r
$$

dimana: 
$\hat{c}(S)$ : nilai perjalanan minimum melalui simpul $S$, dimana $S$ adalah anak dari simpul $R$

$\hat{c}(R)$ : nilai perjalanan minimum yang melalui simpul $R$, dimana $R$ adalah simpul akar

$A(i, j)$ : bobot sisi $(i, j)$ pada matriks tereduksi

$r \quad$ : jumlah semua pereduksi pada proses reduksi matriks untuk simpul $S$

Reduksi matriks simpul anak didasarkan pada matriks simpul induknya. Langkah ini dikerjakan berulang-ulang sampai semua simpul dikunjungi (Margiyani, 2014).

\section{Jenis Penelitian dan Sumber Data}

Jenis penelitian yang digunakan dalam penelitian ini adalah penelitian terapan (Applied Research), yaitu penelitian yang kegunaannya diarahkan dalam rangka memecahkan masalah-masalah pada kehidupan nyata.

Data yang digunakan merupakan data primer, dimana data diperoleh secara langsung dari sumber aslinya, yaitu PT. Sadar Jaya Manunggal cabang Kota Mataram dan dengan bantua google maps dalam menentukan jarak

Tahap-tahap yang dilakukan dalam penelitian ini adalah sebagai berikut:

\section{Mengidentifikasi masalah}

Pada tahap ini dicari sumber pustaka yang berhubungan dengan penelitian yang akan dilakukan dan dipilih bagian dari sumber pustaka sehingga dapat memunculkan ide yang pada akhirnya akan dikaji oleh peneliti sebagai landasan dalam melakukan penelitian.

\section{Merumuskan masalah}

Merumuskan masalah diperlukan agar permasalahan yang dibahas dalam penelitian jelas dan tidak melebar, sehingga akan lebih mudah untuk menentukan pemecahan masalah tersebut.

\section{Mengumpulkan data}

Dalam tahap ini, dilakukan pengumpulan data-data yang diperlukan seperti data jumlah pelanggan dan jarak pelanggan dari PT. Sadar Jaya Manunggal cabang Kota Mataram .

\section{Pengolahan data}

Pengolahan data dapat dilakukan dengan tahap-tahap berikut:

- Memodelkan masalah dalam bentuk Graf
Pada penelitian ini yang menjadi simpul adalah alamat pelanggan atau tujuan pendistribusian bahan bangunan oleh PT. Sadar Jaya Manunggal dan jalan yang menghubungkan tempat yang satu ke tempat lainnya sebagai sisi sedangkan jarak dari masing-masing tempat merupakan bobotnya.

- Membuat Matriks Ketetanggaan

- Menentukan rute terpendek dengan Bobot Minimum

5. Menarik kesimpulan

Setelah tahap-tahap di atas terselesaikan, maka didapatkan hasil rute terpendek pendistribusian bahan bangunan oleh PT. Sadar Jaya Manunggal cabang Kota Mataram ke setiap pelanggan.

\section{Pembahasan}

\subsection{Pengumpulan Data}

Dari data yang diperoleh dari PT. Sadar Jaya Manunggal cabang Kota Mataram, didapatkan sebanyak 7 pelanggan yang berada di Lombok Tengah. Ketujuh pelanggan tersebut yaitu UD. Ikhlas Bersama, Kurnia Jaya, Pos Bangunan, Kunci Pelita, UD. Mitra Utama, UD. Salha, dan UD. Budi Rahman.

\subsection{Memodelkan masalah dalam bentuk graf}

Berdasarkan data yang didapat, dibentuk sebuah graf lengkap dengan jumlah 8 simpul dan 28 sisi. Graf lengkap yang terbentuk dapat dilihat pada gambar berikut

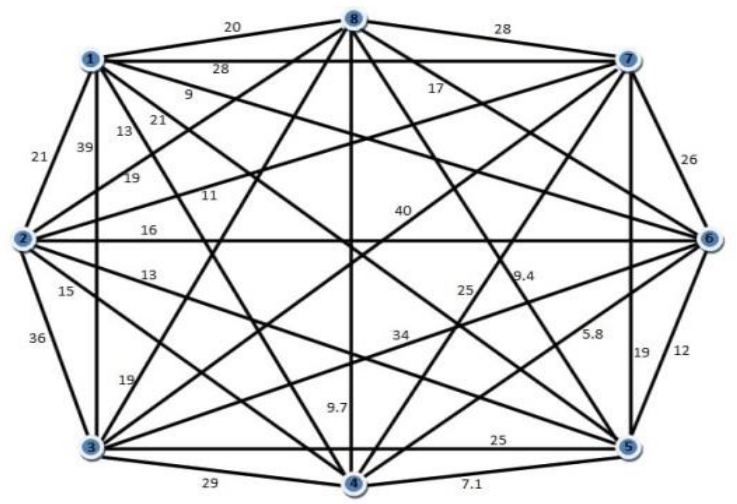

Gambar 1 - Graf Lengkap 


\subsection{Penyelesaian Masalah dengan Algoritma Branch and Bound}

Selanjutnya langkah-langkah penerapan Algoritma Branch and Bound untuk Menentukan Rute Terpendek Pendistribusian Bahan Bangunan oleh PT. Sadar Jaya Manunggal Mataram ke toko-toko bangunan yang ada di Lombok Tengah dapat disajikan sebagai berikut:

a. Representasikan graf kedalam bentuk matriks ketetanggaan

\section{Tabel 1 - Matriks Ketetanggaan}

\begin{tabular}{|c|c|c|c|c|c|c|c|c|}
\hline & $\mathbf{1}$ & $\mathbf{2}$ & $\mathbf{3}$ & $\mathbf{4}$ & $\mathbf{5}$ & $\mathbf{6}$ & $\mathbf{7}$ & $\mathbf{8}$ \\
\hline $\mathbf{1}$ & $\infty$ & 21 & 39 & 13 & 21 & 9 & 28 & 20 \\
\hline $\mathbf{2}$ & 21 & $\infty$ & 36 & 15 & 13 & 16 & 11 & 19 \\
\hline $\mathbf{3}$ & 39 & 36 & $\infty$ & 29 & 25 & 34 & 40 & 19 \\
\hline $\mathbf{4}$ & 13 & 15 & 29 & $\infty$ & 7.1 & 5.8 & 25 & 9.7 \\
\hline $\mathbf{5}$ & 21 & 13 & 25 & 7.1 & $\infty$ & 12 & 19 & 9,4 \\
\hline $\mathbf{6}$ & 9 & 16 & 34 & 5.8 & 12 & $\infty$ & 26 & 17 \\
\hline $\mathbf{7}$ & 28 & 11 & 40 & 25 & 19 & 26 & $\infty$ & 28 \\
\hline $\mathbf{8}$ & 20 & 19 & 19 & 9.7 & 9,4 & 17 & 28 & $\infty$ \\
\hline
\end{tabular}

b. Mereduksi matriks di atas agar lebih sederhana. Reduksi dilakukan dengan cara mengurangi seluruh elemen pada baris atau kolom tertentu dengan nilai terkecil pada elemen baris atau kolom tertentu sehingga terdapat setidaknya satu nilai 0 pada baris atau kolom tersebut.

Tabel 2 - Reduksi Baris Matriks Ketetanggaan

\begin{tabular}{|c|c|c|c|c|c|c|c|c|}
\hline & $\mathbf{1}$ & $\mathbf{2}$ & $\mathbf{3}$ & $\mathbf{4}$ & $\mathbf{5}$ & $\mathbf{6}$ & $\mathbf{7}$ & $\mathbf{8}$ \\
\hline $\mathbf{1}$ & $\infty$ & 12 & 30 & 4 & 12 & 0 & 19 & 11 \\
\hline $\mathbf{2}$ & 10 & $\infty$ & 25 & 4 & 2 & 5 & 0 & 8 \\
\hline $\mathbf{3}$ & 20 & 17 & $\infty$ & 10 & 6 & 15 & 21 & 0 \\
\hline $\mathbf{4}$ & 7.2 & 9.2 & 23.2 & $\infty$ & 1.3 & 0 & 19.2 & 3.9 \\
\hline $\mathbf{5}$ & 13.9 & 5.9 & 17.9 & 0 & $\infty$ & 4.9 & 11.9 & 2.3 \\
\hline $\mathbf{6}$ & 3.2 & 10.2 & 28.2 & 0 & 6.2 & $\infty$ & 20.2 & 11.2 \\
\hline $\mathbf{7}$ & 17 & 0 & 29 & 14 & 8 & 25 & $\infty$ & 17 \\
\hline $\mathbf{8}$ & 10.6 & 9.6 & 9.6 & 0.2 & 0 & 7.6 & 18.6 & $\infty$ \\
\hline
\end{tabular}

Karena pada kolom 1 dan 3 tidak terdapat nilai nol maka akan dilakukan reduksi kolom.

\section{Tabel 3 - Reduksi Kolom 1 dan 3 Matriks Ketetanggaan}

\begin{tabular}{|c|c|c|c|c|c|c|c|c|}
\hline & $\mathbf{1}$ & $\mathbf{2}$ & $\mathbf{3}$ & $\mathbf{4}$ & $\mathbf{5}$ & $\mathbf{6}$ & $\mathbf{7}$ & $\mathbf{8}$ \\
\hline $\mathbf{1}$ & $\infty$ & 12 & 20.4 & 4 & 12 & 0 & 19 & 11 \\
\hline $\mathbf{2}$ & 6.8 & $\infty$ & 15.4 & 4 & 2 & 5 & 0 & 8 \\
\hline $\mathbf{3}$ & 16.8 & 17 & $\infty$ & 10 & 6 & 15 & 21 & 0 \\
\hline $\mathbf{4}$ & 4 & 9.2 & 13.6 & $\infty$ & 1.3 & 0 & 19.2 & 3.9 \\
\hline $\mathbf{5}$ & 10.7 & 5.9 & 8.3 & 0 & $\infty$ & 4.9 & 11.9 & 2.3 \\
\hline $\mathbf{6}$ & 0 & 10.2 & 18.6 & 0 & 6.2 & $\infty$ & 20.2 & 11.2 \\
\hline $\mathbf{7}$ & 13.8 & 0 & 19.4 & 14 & 8 & 25 & $\infty$ & 17 \\
\hline $\mathbf{8}$ & 7.4 & 9.6 & 0 & 0.2 & 0 & 7.6 & 18.6 & $\infty$ \\
\hline
\end{tabular}

c. Selanjutnya, proses reduksi ini akan menghasilkan nilai batas simpul akar atau $\hat{c}($ root $)$, yang didapat dari penjumlahan semua elemen pengurangan tadi.

Jadi,

$\hat{c}($ root $)=9+11+19+5.8+7.1+5.8+$ $11+9.4+3.2+9.6=90,9$

Disini berarti telah dibangkitkan pohon ruang status yang baru berisi satu buah simpul dengan bobot 90,9 .

d. Kemudian dihitung simpul - simpul lain pada pohon ruang status sebagai berikut :

Tabel 4 - Lintasan 1,2

\begin{tabular}{|c|c|c|c|c|c|c|c|c|}
\hline & $\mathbf{1}$ & $\mathbf{2}$ & $\mathbf{3}$ & $\mathbf{4}$ & $\mathbf{5}$ & $\mathbf{6}$ & $\mathbf{7}$ & $\mathbf{8}$ \\
\hline $\mathbf{1}$ & $\infty$ & $\infty$ & $\infty$ & $\infty$ & $\infty$ & $\infty$ & $\infty$ & $\infty$ \\
\hline $\mathbf{2}$ & $\infty$ & $\infty$ & 15.4 & 4 & 2 & 5 & 0 & 8 \\
\hline $\mathbf{3}$ & 16.8 & $\infty$ & $\infty$ & 10 & 6 & 15 & 21 & 0 \\
\hline $\mathbf{4}$ & 4 & $\infty$ & 13.6 & $\infty$ & 1.3 & 0 & 19.2 & 3.9 \\
\hline $\mathbf{5}$ & 10.7 & $\infty$ & 8.3 & 0 & $\infty$ & 4.9 & 11.9 & 2.3 \\
\hline $\mathbf{6}$ & 0 & $\infty$ & 18.6 & 0 & 6.2 & $\infty$ & 20.2 & 11.2 \\
\hline $\mathbf{7}$ & 13.8 & $\infty$ & 19.4 & 14 & 8 & 25 & $\infty$ & 17 \\
\hline $\mathbf{8}$ & 7.4 & $\infty$ & 0 & 0.2 & 0 & 7.6 & 18.6 & $\infty$ \\
\hline
\end{tabular}

Karena pada baris ke-7 tidak terdapat nilai nol maka akan dilakukan reduksi baris. Sehingga diperoleh : 
Tabel 5 - Reduksi Baris ke-7 Lintasan 1,2

\begin{tabular}{|c|c|c|c|c|c|c|c|c|}
\hline & $\mathbf{1}$ & $\mathbf{2}$ & $\mathbf{3}$ & $\mathbf{4}$ & $\mathbf{5}$ & $\mathbf{6}$ & $\mathbf{7}$ & $\mathbf{8}$ \\
\hline $\mathbf{1}$ & $\infty$ & $\infty$ & $\infty$ & $\infty$ & $\infty$ & $\infty$ & $\infty$ & $\infty$ \\
\hline $\mathbf{2}$ & $\infty$ & $\infty$ & 15.4 & 4 & 2 & 5 & 0 & 8 \\
\hline $\mathbf{3}$ & 16.8 & $\infty$ & $\infty$ & 10 & 6 & 15 & 21 & 0 \\
\hline $\mathbf{4}$ & 4 & $\infty$ & 13.6 & $\infty$ & 1.3 & 0 & 19.2 & 3.9 \\
\hline $\mathbf{5}$ & 10.7 & $\infty$ & 8.3 & 0 & $\infty$ & 4.9 & 11.9 & 2.3 \\
\hline $\mathbf{6}$ & 0 & $\infty$ & 18.6 & 0 & 6.2 & $\infty$ & 20.2 & 11.2 \\
\hline $\mathbf{7}$ & 5,8 & $\infty$ & 11.4 & 6 & 0 & 17 & $\infty$ & 9 \\
\hline $\mathbf{8}$ & 7.4 & $\infty$ & 0 & 0.2 & 0 & 7.6 & 18.6 & $\infty$ \\
\hline
\end{tabular}

$$
\begin{aligned}
\hat{c}(S) & =\hat{c}(R)+A(i, j)+r \\
& =90,9+6,8+8 \\
& =105,7
\end{aligned}
$$

e. Langkah selanjutnya yaitu melakukan perhitungan pada lintasan lainnya seperti pada lintasan sebelumnya sehingga didapatkan hasil sebagai berikut:

\begin{tabular}{|c|c|c|c|c|}
\hline Lintasan & $\hat{c}(R)$ & $A(i, j)$ & $r$ & $\hat{c}(S)$ \\
\hline 1,3 & 90,9 & 16,8 & 0 & 107,7 \\
\hline 1,4 & 90,9 & 4 & 2,3 & 97,2 \\
\hline 1,5 & 90,9 & 10,7 & 0 & 101,6 \\
\hline 1,6 & 90,9 & 0 & 4 & 94,9 \\
\hline 1,7 & 90,9 & 13,8 & 2 & 106,7 \\
\hline 1,8 & 90,9 & 7,4 & 6 & 104,3 \\
\hline
\end{tabular}

Dari semua hasil $\hat{c}(S)$, lintasan yang paling minimum yaitu lintasan 1,6. Ambil nilai $\hat{c}(S)$ yang paling minimum, kemudian dilakukan perhitungan nilai $\hat{c}(S)$ seperti perhitungan sebelumnya dan didapatkan hasil sebagai berikut:

\begin{tabular}{|c|c|c|c|c|}
\hline Lintasan & $\hat{c}(R)$ & $A(i, j)$ & $r$ & $\hat{c}(S)$ \\
\hline $1,6,2$ & 94,9 & 10,2 & 113,1 & 107,1 \\
\hline $1,6,3$ & 94,9 & 18,6 & 0 & 113,5 \\
\hline $1,6,4$ & 94,9 & 0 & 2,3 & 97,2 \\
\hline $1,6,5$ & 94,9 & 6,2 & 0 & 101,1 \\
\hline $1,6,7$ & 94,9 & 20,2 & 2 & 117,1 \\
\hline $1,6,8$ & 94,9 & 11,2 & 6 & 112,1 \\
\hline
\end{tabular}

Dari semua hasil $\hat{c}(S)$, ambil nilai $\hat{c}(S)$ yang paling minimum. Lintasan yang paling minimum pada perhitungan sebelumnya yaitu lintasan $1,6,4$. Setelah itu dilakukan perhitungan nilai $\hat{c}(S)$ seperti pada perhitungan sebelumnya dan didapatkan hasil sebagai berikut:

\begin{tabular}{|c|c|c|c|c|}
\hline Lintasan & $\hat{c}(R)$ & $A(i, j)$ & $r$ & $\hat{c}(S)$ \\
\hline $1,6,4,2$ & 97,2 & 11 & 8 & 116,2 \\
\hline $1,6,4,3$ & 97,2 & 13,6 & 2,8 & 113,6 \\
\hline $1,6,4,5$ & 97,2 & 1,3 & 2,8 & 101,3 \\
\hline $1,6,4,7$ & 97,2 & 19,2 & 2,8 & 119,2 \\
\hline $1,6,4,8$ & 97,2 & 8,3 & 6 & 111,5 \\
\hline
\end{tabular}

Dari semua hasil $\hat{c}(S)$, ambil nilai $\hat{c}(S)$ yang paling minimum. Lintasan yang paling minimum yaitu lintasan $1,6,4,5$. Setelah itu dilakukan perhitungan nilai $\hat{c}(S)$ seperti perhitungan sebelumnya dan didapatkan hasil sebagai berikut:

\begin{tabular}{|c|c|c|c|c|}
\hline Lintasan & $\hat{c}(R)$ & $A(i, j)$ & $r$ & $\hat{c}(S)$ \\
\hline $1,6,4,5,2$ & 101,3 & 3,3 & 7 & 108,3 \\
\hline $1,6,4,5,3$ & 101,3 & 6 & 0,6 & 107,9 \\
\hline $1,6,4,5,7$ & 101,3 & 9,6 & 0 & 110,9 \\
\hline $1,6,4,5,8$ & 101,3 & 0 & 0 & 101,3 \\
\hline
\end{tabular}

Lintasan yang paling minimum yaitu lintasan 1,6,4,5,8. Kemudian dilakukan perhitungan nilai $\hat{c}(S)$ seperti perhitungan sebelumnya dan didapatkan hasil sebagai berikut:

\begin{tabular}{|c|c|c|c|c|}
\hline Lintasan & $\hat{c}(R)$ & $A(i, j)$ & $r$ & $\hat{c}(S)$ \\
\hline $1,6,4,5,8,2$ & 101,3 & 9,6 & 29,4 & 140,3 \\
\hline $1,6,4,5,8,3$ & 101,3 & 0 & 10 & 111,3 \\
\hline $1,6,4,5,8,7$ & 101,3 & 18,6 & 25,4 & 145,3 \\
\hline
\end{tabular}

Lintasan yang paling minimum yaitu lintasan $1,6,4,5,8,3$. Kemudian dilakukan perhitungan nilai $\hat{c}(S)$ seperti perhitungan sebelumnya dan didapatkan hasil sebagai berikut:

\begin{tabular}{|c|c|c|c|c|}
\hline Lintasan & $\hat{c}(R)$ & $A(i, j)$ & $r$ & $\hat{c}(S)$ \\
\hline $1,6,4,5,8,3,2$ & 111,3 & 7 & 7 & 127,3 \\
\hline $1,6,4,5,8,3,7$ & 111,3 & 11 & 0 & 122,3 \\
\hline
\end{tabular}


Dan lintasan yang paling minimum yaitu lintasan $1,6,4,5,8,3,7$. Sehingga untuk perhitungan nilai $\hat{c}(S)$ pada lintasan terakhir yaitu lintasan $1,6,4,5,8,3,7,2$ didapatkan hasil sebagai berikut:

$$
\begin{aligned}
\hat{c}(S) & =\hat{c}(R)+A(i, j)+r \\
& =122,3+0+0 \\
& =122,3
\end{aligned}
$$

Dari keseluruhan hasil perhitungan, didapatkan rute dengan bobot paling minimum melalui simpul 1-6-45-8-3-7-2-1 dengan bobot 122,3. Adapun bentuk percabangan dari langkah-langkah yang sudah dilakukan, dapat dilihat pada gambar dibawah ini:

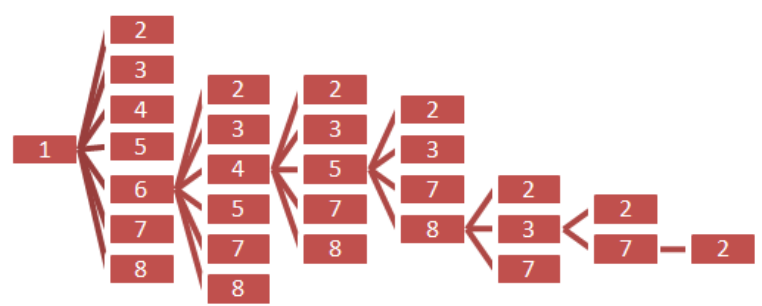

Gambar 2 - Branch and Bound Rute Pendistribusian Barang oleh PT. Sadar Jaya Manunggal

\section{Kesimpulan}

Berdasarkan hasil pengamatan, analisis graf dan pembahasan dapat disimpulkan bahwa persoalan optimalisasi dari Travelling Salesman Problem (TSP) pada pendistribusian bahan bangunan PT Sadar Jaya Manunggal khususnya untuk daerah Lombok Tengah dapat diselesaiakan dengan menggunakan algoritma Branch and Bounch yaitu dengan membentuk matriks ketetanggan dari graf lengkap. Kemudian melakukan reduksi pada matriks awal seperti pada pembahasan, sehingga dapat diperoleh solusi dari persoalan TSP, yaitu berupa rute terpendek dari PT. Sadar Jaya Manunggal Mataram ke UD. Mitra Utama, Pos Bangunan - Kunci Pelita, UD. Budi Rahman, Kurnia Jaya, UD. Salha, Ikhlas Bersama, dan kembali ke PT. Sadar Jaya Manunggal Mataram dengan total jarak 122,3 km.

\section{DAFTAR PUSTAKA}

Amin, Rahma Aulia, dkk. (2006). Traveling Salesman Problem. Bandung: Institut Teknologi Bandung.

Avidianto, Devo. (2010). Pengertian Distribusi dan Fungsi Distribusi. Tangerang: Banten.

Eko, Budi Purwanto. (2008). Perancangan dan Analisis Algoritma. Yogyakarta: Graha Ilmu.

Hillier, F dan Lieberman, G.J. (2001). Introduction to Operation Reasearch Seventh Editon. New York : Mc Graw Hill.

Lipschutz, R. D. (2002). The Clash of Governmentalities. The Fall of the UN Republic and America's Reach for Empire. Contemporary Security Policy, 23: 3, 214-31.

Margiyani, Sri dan Mussafi, Noor Saif Muhammad. (2014). Aplikasi Algoritma Branch and Bound untuk Optimasi Jalur Pemadam Kebakaran Kota Yogyakarta. Yogyakarta : UIN Sunan Kalijaga.

Sitorus, P. (1997). Program Linier. Universitas Trisakti: Jakarta.

Suyanto. (2010). Algoritma Optimasi (Deterministik atau Probabilistik). Yogyakarta: Graha Ilmu. 